\title{
THE EFFECT OF EXPLOSIVE POWER LEG MUSCLE, FOOT-EYE COORDINATION, REACTION SPEED AND CONFIDENCE IN THE ABILITY OF THE CRESCENT KICK
}

\author{
Padli Arsyad ${ }^{1}$, A Sofyan Hanif ${ }^{2}$, James Tangkudung ${ }^{3}$ \\ State University of Jakarta \\ arsyadpadli@gmail.com ${ }^{1}$ \\ asofyanhanif@unj.ac.id ${ }^{2}$ \\ jamestangkudung@unj.ac.id ${ }^{3}$
}

\begin{abstract}
The aim of this study was to determine the effect of leg muscle explosive power, foot-eye coordination, reaction speed and confidence in the ability of the crescent kick. This study uses a survey to look at the relationship between variable. Data analysis techniques using path analysis (path analysis) Path analysis techniques can be used to examine the effect of direct and indirect factors influence explosive power leg muscle, foot-eye coordination, reaction speed and trust themselves on the ability of 30 athletes crescent kick parried Lampung, the provincial government of Lampung, preparation in Porwil Bangka Belitung.Overall it can be concluded that after the test statistics of the empirical data which have been obtained from the field, it can be said that the four independent variables that explosive power leg muscle, coordination ankles, reaction speed and confidence to have a positive influence directly significantly from the ability to kick sickle athletes martial Lampung, the provincial government of Lampung, preparation in Porwil Bangka Belitung.
\end{abstract}

Keywords: explosive power leg muscle, foot-eye coordination, reaction speed and confidence and the ability of the crescent kick

Pencak silat is part of Indonesian culture. The term martial is widely known in Southeast Asia, but specifically in Indonesia the term used is martial arts. The term was used since 1948 to unify the various streams of traditional martial arts that developed in Indonesia. The name "pencak" is used in Java, while "silat" is used in Sumatra, Malay Peninsula and Kalimantan. In silat, we learn rhythm and self-confidence, we learn to move with "feelings," or with more subtle feelings. In silat, our body is a dangerous weapon but other objects can be used as weapons. Some traditional weapons such as kris, sarong, kerambit, and machetes.

Pencak Silat itself is one of the cultural results of the Malay family, which arises and develops rapidly from time to time. According to Winandi a martial art expert from PerPI Harimurti University in Yogyakarta cited by Siswantoyo the term pencak comes from the Javanese language and consists of the word "pen" which means proper and the word "cak" which means application. Thus pencak means proper martial arts, both ways and the use of pencak. In its development, the term "pencak" is more of an artistic element and the appearance of the beauty of movement, while "silat" is the core of martial arts in battle. In Minangkabau legend, silat (Minangkabau language: silek) was created by Datuk Suri Diraja from Pariangan, Tanah Datar at the foot of Mount Marapi in the 11th century. Then the silek was brought and developed by Minang migrants throughout Southeast Asia. Good martial arts capabilities require the support of good physical condition elements such as speed and agility can provide faster motion capability. With many repetitive methods, the quick and fast skill of the crescent can be achieved and displayed in the game. The much-needed physical component for producing sickle-kick skills is the explosive power of the leg muscles, coordination, speed of reaction and self-confidence.

The research problems that can be raised are as follows: (1) Is there influence of limb muscle explosive effect directly on skill crescent skill, (2) Is there influence of eye-foot coordination directly influence to skill crescent skills, (3) Is there influence of velocity the reaction has direct effect on the skill of the sickle kick, (4) Is there a confidence effect directly affect the skill of the sickle kick, (5) Is there influence of explosive muscle limb effect directly to confidence, (6) Is there influence of eye-foot coordination effect directly to confidence, (7) Is there influence of speed of reaction directly influence 
to self-confidence, (8) Is there influence of limb muscle explosion effect directly to eye-foot coordination, (9) Is there influence of explosive muscle power directly speed of reaction, (10) What is accosted the influence of foot-eye coordination directly affects the rate of reaction.

\section{Sickling kick skills}

The kick judged in the martial arts game is a kick that strikes the target, which can be a legitimate and valuable target is "Togok" ie the body parts except the neck up and from the center to the genitals: Chest, Stomach (center up), Ribs left and right, Back or back of the body, IPSI (2012: 13). The kicks allowed in the battle category there are several kinds, including straight kicks, side kicks, back kick and one of them, sickle kick.

According to Johansyah (2011:29) sickle kick is a half-circle kick into the inside, targeting all parts of the body, with the back of the foot or fingers of the foot.

\section{Explosive muscle limb power}

Explosive power is one of the elements of physical condition required in an effort to improve sports performance. One of the factors of physical condition that determines the strength of the sturdy horses in the sickle kick, the maximum, and the strength of the sickle is the explosive force of the leg muscles.

According to Peter M. Mc Ginnis (2005: 112) explosive power is the product of the forces applied by a fast muscle with strong controws being more powerful than the slowly applying muscle strength. From other perspectives explosive power is the level of time during which physical work is being performed.

\section{Eye-foot coordination}

In the sport of martial arts, the eye-foot coordination is deeply embraced, through the eye's eye, we can see the movements to be performed by the counterpart, and in the process through the brain. Then responded by members of the body, especially the foot to move.

According to James tangkudung (2006: 44) Nerves is an organ that serves to organize a neat cooperation in the organization and coordination of cell body activities.

Furthermore, according to James Tangkudung (2006: 8) To display a movement technique skills, the motor skills needed as one of the supporting factors. Thus it can be said that without having good coordination, it will be difficult to adjust the rhythm of motion when presenting good technique. Exercise is a recurring and increasing process to increase potential in order to achieve maximum performance. Athletes follow a long-term training program to improve the condition of body and soul compete in an appearance.

\section{Reaction Speed}

Physical component factors that are needed in the sport is one of the speed of reaction. The speed of reactions in many sports requires that the components of speed and flexibility are essential physical components. At sibling the rate of reaction is crucial to achieving a high performance improvement of achieving the best sickle kick in a martial arts match.

According to Sharkey (2003: 167) the total movement speed includes reaction time and movement time. Reaction time (time of stimulation, such as head movement, characteristic of a person willing to kick, beginning to beginning of movement) is a function of the nervous system. Any significant improvement in reaction time should be achieved by alerting precautionary precautions and by repeating the appropriate response, which reduces central nervous system process time. Movement time, interval from beginning to end of movement, as it increases (lowered) with proper power training. The key to success depends on the principle of specificity: Movement must be specific to the sport. Specificity applies to the level of movement and obstacles used, which means the exercise must simulate the movement as closely as possible.

The reaction speed consists of 2 types: 1). Reaction rate simple / reflex (simple RT), 2). Reaction speed (choice RT). If there is only one response (simple reaction time) it will take a short time to react. If there is some response (optional reaction time) then it will take longer to determine the response to be completed.

\section{The Nature of Confidence}


According to Monti (2000: 245) believe the Self is convincing in the ability and self-assessment in doing the task and choose an effective approach. Believing yourself closely related to the philosophy of self-fulfillment and self-belief. This includes a belief in its ability to cope with an increasingly challenging environment and trust in its decisions or opinions.

In general, confidence is understood as one's belief in his ability to do certain things. This means that confidence and confidence arise only when someone does something that he or she is capable of doing. Johnson and Swidley describe self-confidence is a person's belief based on his ability to achieve the desired things that are closely related to his beliefs.

Self-confidence describes a person's personality for self-respect and believes in the ability to do things.

\section{METHOD}

The method used in this study is using survey method by looking at causality between variables. Technique of data analysis by using path analysis (path analysis). This pathway analysis technique can be used to examine the direct and indirect effects of the leg muscle explosive power factor, eye-foot coordination, reaction speed, self-confidence and sickle-kick skills.

As for the constellation of research can be seen in the picture below:

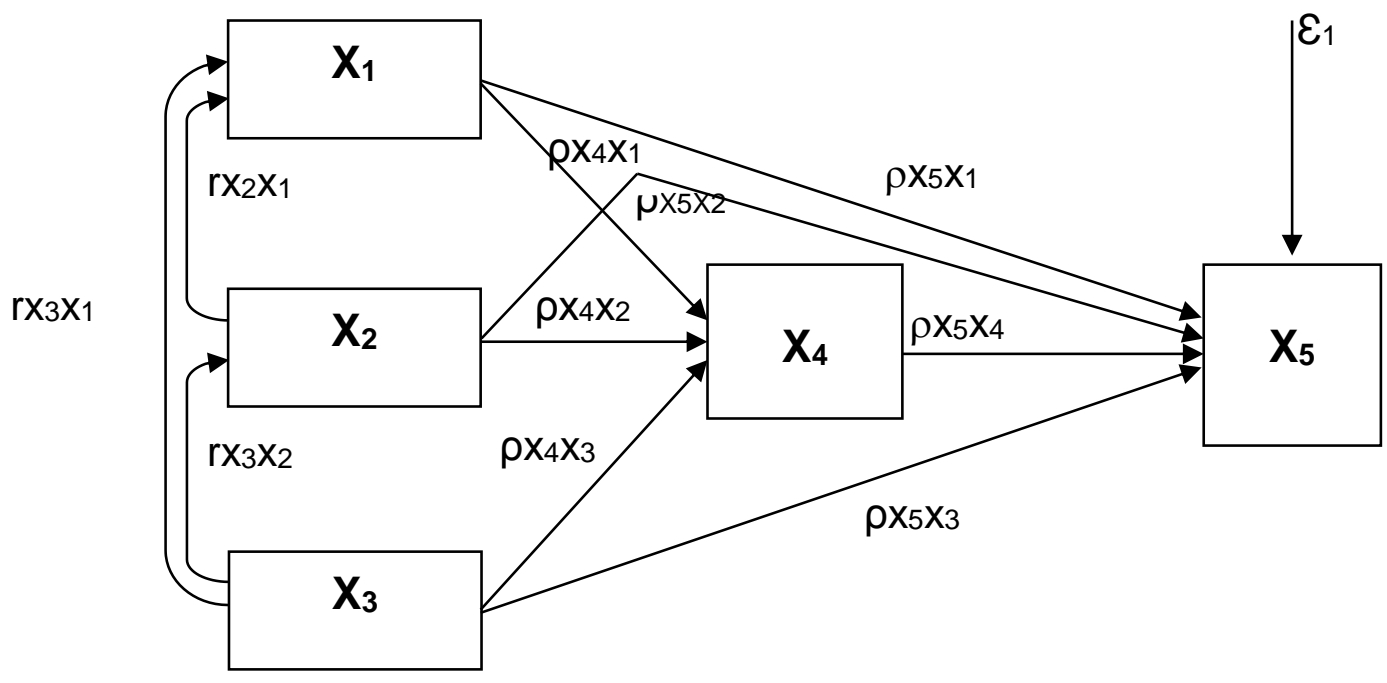

\section{Figure 1. Model of Research Constellation}

The analytical technique used in this study is the data analysis technique used in this study are as follows: 1) Descriptive statistics, is statistics aimed at providing data description of each research variable, 2) Test requirements analysis are: (1) test normality, and (2) homogeneity test. The explanations of the two tests are as follows: First, the normality test to test the assumption of population normality, by the Lilliefors test. Second, testing the homogeneity of variance with Bartlett test, Wisnijati Basuki Abdulah (2013: 40). After the analytical requirements are met followed by testing the research hypothesis. Technique of analysis with regression and correlation analysis technique. The first hypothesis testing, the second hypothesis, and the third hypothesis were performed by simple Pearson Product Moment regression and correlation analysis technique. The fourth hypothesis test was tested by multiple regression and correlation analysis techniques.

\section{RESEARCH RESULT}

Discussion of research results proposed as follows: 1) Legality of leg muscle has a positive effect on skill sickle skills, this is evidenced by the obtained value t-count $=4,068$ and t-table $(0,05,30)$ $=1,697$ at significant level 0.000 smaller than $\alpha=0.05$, thus $\mathrm{t}$-count is larger than $\mathrm{t}$-table, $\mathrm{H} 0$ is rejected, and $\mathrm{H} 1$ is accepted. 2) Foot-eye coordination positively affects the skill of sickle kick, this is proved by $\mathrm{t}$-count $=4,405$ and $\mathrm{t}$-table $(0,05)=1,697$ at significant level 0.000 smaller than $\alpha=0,05$, thus $\mathrm{t}$-count bigger than t-table, means $\mathrm{H} 0$ is rejected, and $\mathrm{H} 1$ accepted. 3) The reaction speed has a positive effect 
on the skill of the crescent, this is proved by the $t$-count $=6,168$ and $t$-table $(0,05)=1,697$ at the significant level 0.000 , so t-count is bigger than t-table, $\mathrm{H} 0$ is rejected, and $\mathrm{H} 1$ is accepted. 4) Confidence positively affects the skill of sickle kick, this is proved by $\mathrm{t}$-count $=6,627$ and $\mathrm{t}$-table $(0,05)$ $=1,697$ at significant level 0.000, so t-count is bigger than t-table, $\mathrm{H} 0$ is rejected, and $\mathrm{H} 1$ is accepted. 5) Limb muscle explosive power positively affect kayak reaction speed, this is proved by obtained tcount $=2.504$ and $\mathrm{t}$-table $(0,05)=1,697$ with significant level 0,018 smaller than $\alpha=0,05$, hence $\mathrm{t}$ count bigger than t-table, means $\mathrm{H} 0$ is rejected, and $\mathrm{H} 1$ accepted. 6) Foot-eye coordination has a positive effect on the speed of the reaction, this is evidenced by the obtained value $t$-count $=2.773$ and $t$-table $(0.05)=1.697$ with a significant level of 0.010 smaller than $\alpha=0.05$, thus $t$ count is greater than $t$-table , means $\mathrm{H} 0$ is rejected, and $\mathrm{H} 1$ accepted. 7) Confidence has a positive effect on the speed of the reaction, this is evidenced by the obtained value $t$-count $=3.325$ and t-table $(0.05)=1.697$ with a significant level of 0.002 smaller than $\alpha=0.05$, thus t count larger than t-table, $\mathrm{H} 0$ is rejected, and $\mathrm{H} 1$ is accepted. 8) Limb muscle explosive effect directly positive to eye-foot coordination, this is evidenced by the obtained t-count $=9,820$ and t-table $(0,05)=1,697$ with significant level 0.000 smaller than $\alpha=0,05$, thus t-count more large of t-table, means $\mathrm{H} 0$ is rejected, and $\mathrm{H} 1$ accepted. 9) Limb muscle explosive power directly positive effect on the speed of the reaction, this is evidenced by the obtained value $t$ count $=9,174$ and $t$-table $(0,05)=1,697$ with significant level 0,001 smaller than $\alpha=0,05$, thus t-count bigger than t-table, means $\mathrm{H} 0$ is rejected, and $\mathrm{H} 1$ accepted. 10) Foot-eye coordination has a direct positive effect on the speed of the reaction, this is evidenced by the $t$-count value $=10.079$ and $t$-table $(0.05)=1.697$ with a significant level of 0.000 smaller than $\alpha=0.05$, thus $t$ count is greater than $t$-table, means $\mathrm{H} 0$ is rejected, and $\mathrm{H} 1$ accepted.

\section{DISCUSSION}

Based on the results of hypothesis testing, it turns out the eight proposed hypotheses show positive correlated results. The description of each hypothesis can be explained as follows:

\section{Limb muscle explosive power positively affects the skill of sickle kick.}

The results of the hypothesis that the crescent sickness skill (X5) and explosive muscle power of the limbs (X1) yielded an alleged model, that $\mathrm{Y}=28,607+0,463 \mathrm{X} 1$. The results of variance analysis (ANAVA) on this model are presented in Table 4.8. In this table it can be seen that the value obtained F-count 16.545 obtained value F-table $=(0.05,1: 28)$ of 4.20 with a significant level of 0.000 which means that the $\mathrm{F}$ test shows the value of significance $(\mathrm{p})$ is smaller than $\alpha 0.05$. Thus it can be argued that the regression equation is significant.

Double correlation coefficient (R) in table 4.9 obtained value of 0.609 after consultation with r-table on degrees of freedom 29 with $\alpha=0.05$ of 0.311 then variable X1 to X5 significantly positive correlated.

R Square (coefficient of determination) obtained value of 0.371 , which means $37.1 \%$ of the total variation of crescent-skill skills (X5) caused by multiple regression relationships with variable leg muscle explosive power (X1). This means that $37.1 \%$ limb muscle explosive power data (X1) has a direct effect on skill kick skills (X5) and the rest of $62.9 \%$ or $(100 \%-37.1 \%=62.9 \%)$ is caused by factors - other factors such as: mental state, nutrition, recovery, health condition of athletes, and others.

Furthermore, the calculation result in regression coefficient table, obtained t-count $=4,068$ and t-table $(0,05,30)=1,697$ at significant level 0.000 smaller than $\alpha=0,05$, thus $t$-count bigger than t-table, mean $\mathrm{H} 0$ refused, and $\mathrm{H} 1$ accepted. From the calculation results can be stated that the hypothesis proposed: power muscle leg explosion (X1) directly positive effect on skill crescent (X5) is accepted. The results of the proposed hypothesis analysis provide findings that explosive muscle limb power directly affects the skill of the crescent. These findings mean that if you want to improve sickle-kick skills it can be done through increased muscle limb power. 
Based on the termination coefficient, also obtained the determination value of 0.371 . This means that variation in sickle-kick skills can be explained by the variation in explosive muscle power of $37.1 \%$.

The findings in this study are in line with the theoretical studies suggested earlier that a good limb muscle explosive power will be able to show a good achievement as well. Thus it can be said that sickle-kicking skills can be improved when looking at the muscle power of the limbs to improve the skill of the crescent.

\section{Foot-eye coordination has a direct positive effect on sickle-kick skills.}

The results of the hypothesis suggesting that sickle-kicking skills (X5) and eye-foot coordination (X2) resulted in the alleged model, that $\mathrm{Y}=23.964+0.562 \mathrm{X} 2$. The results of variance analysis (ANAVA) on this model are presented in Table 4.10. In this table can be seen that the obtained value F-count 19.407 obtained value F-table $=(0.05,1: 28)$ of 4.20 with a significant level of 0.000 . Thus it can be argued that the regression equation is significant.

Double correlation coefficient $(\mathrm{R})$ obtained value of 0.640 after consultation with $\mathrm{r}$-table on degrees of freedom 29 with $\alpha=0.05$ of 0.311 then the variable X2 to X5 correlated positively significantly.

R Square (coefficient of determination) obtained value of 0.409 , which means $40.9 \%$ of the total skill sickle caliber variation (X5) is caused by the multiple regression of eye-foot coordination variation (X2). This means that $40.9 \%$ eye-foot coordination data (X2) gives a direct impact on crescentskill skills (X5) and the rest of $59.1 \%$ or $(100 \%-40.9 \%=59.1 \%)$ is caused by factors - other factors such as: mental state, nutrition, recovery, health condition of athletes, and others.

Furthermore, the result of t-test calculation on regression coefficient table, obtained $\mathrm{t}$-count $=$ 4,405 and t-table $(0,05)=1,697$ at significant level 0.000 less than $\alpha=0,05$, thus t-count bigger than ttable, mean $\mathrm{H} 0$ rejected, and $\mathrm{H} 1$ accepted. From the results of the calculation can be stated that the hypothesis proposed, eye-foot coordination (X2) have a direct positive effect on skill crescent (X5) is accepted. The results of the proposed hypothesis analysis provide findings that eye-foot coordination has a direct positive effect on sickle-kick skills. This finding means that if you want to improve sicklekick skills it can be done through increased eye-foot coordination.

The findings in this study are in line with the theoretical studies put forward that good eye-toeye coordination will support good performance. Thus it can be said that sickle-kick skills can be improved when supported by good eye-foot coordination.

Simple correlation coefficient level between eye-foot coordination with sickle-kick skills resulting from the control of independent variables, either individually or collectively. This suggests that there is a linkage between eye-foot coordination variables with explosive muscle limb power and the association between eye-foot coordination variables and reaction rates. Although there are related independent variables of eye-to-eye coordination with other independent variables such as the motivation of pace and reaction rate but the result is so small that the linkage between explosive muscle limb power with sickle-kick skills.

\section{The reaction rate has a direct positive effect on the skill of the sickle kick.}

The results of the hypothesis suggest that crescent-shooting skills (X5) and reaction velocity (X3) yielded an alleged model, that $\mathrm{Y}=17.483+0.713 \mathrm{X} 3$. The results of variance analysis (ANAVA) on this model are presented in Table 4.12. In this table it can be seen that the value obtained F-count 38.049 obtained value F-table $=(0.05,1: 28)$ of 4.20 with a significant level of 0.000 . Thus it can be argued that the regression equation is significant.

Double correlation coefficient (R) obtained value of 0.759 after consultation with r-table on degrees of freedom 29 with $\alpha=0.05$ of 0.311 then the variable X3 to X5 correlated positively significantly. 
R Square (coefficient of determination) obtained a value of 0.576 , which means $57.6 \%$ of the total variation of skill crescent (X5) is caused by the variable regression relationship variable speed of reaction (X3). This means that $57.6 \%$ of the reaction rate data (X3) gives a direct effect on the skill of the crescent (X5) and the rest of $42.4 \%$ or $(100 \%-57.6 \%=42.4 \%)$ is caused by factors such as: mental state, nutrition, recovery, health conditions athletes, and others.

Furthermore, from t-test analysis, $t$-count $=6,168$ and t-table $(0,05)=1,697$ at significant level 0.000 , so t-count is bigger than t-table, H0 is rejected, and H1 is accepted. From the results of the calculation can be stated that the hypothesis proposed: reaction speed (X3) directly positive effect on skill crescent (X5) is accepted. The results of this hypothesis analysis provide findings that the reaction rate has a direct positive effect on the skill of the crescent. These findings mean that if you want to improve sickle-kick skills it can be done through increasing the speed of the reaction. The findings in this study are in line with the theoretical studies put forward that the effect of a good reaction speed will be able to show good sickle-kick skills as well. Thus it can be said that sickle-kick skills can increase as the reaction rate increases so that athlete performance will also increase.

\section{Confidence has a direct positive effect on the skill of the sickle.}

The results of the hypothesis suggest that sickle crater skill (X5) and self-confidence (Xy) produce an alleged model, that $\mathrm{Y}=17.225+0.707 \mathrm{X} 4$. The results of variance analysis (ANAVA) on this model are presented in Table 4.13. In this table can be seen that the obtained value F-count 43.915 obtained value F-table $=(0.05,1: 28)$ of 4.20 with a significant level of 0.000 . Thus it can be argued that the regression equation is significant.

Double correlation coefficient $(\mathrm{R})$ obtained value equal to 0,781 after consultation with r-table at degrees of freedom 29 with $\alpha=0,05$ equal to 0,311 then variable X4 to X5 significant positive correlation.

R Square (coefficient of determination) obtained a value of 0.611 , which means $61.1 \%$ of the total variation of skill kick skills (X5) caused by multiple confidence variables confident variable (X4). This means that $61.1 \%$ confident data (X4) has a direct effect on skill crescent skills (X5) and the rest of $38.9 \%$ or $(100 \%-61.1 \%=38.9 \%)$ is due to factors such as: mental state, nutrition, recovery, health conditions athletes, and others.

Furthermore, from t-test analysis, $t$-count $=6,627$ and t-table $(0,05)=1,697$ at significant level 0.000 , so t-count is bigger than t-table, H0 is rejected, and H1 is accepted. From the results of the calculation can be stated that the hypothesis proposed: confidence (X4) directly positive effect on skill crescent (X5) is accepted. The results of this hypothesis analysis provide findings that the reaction rate has a direct positive effect on the skill of the crescent. These findings mean that if you want to improve sickle-kick skills it can be done through increased confidence.

The findings in this study are in line with the theoretical studies put forward that the effect of a good reaction speed will be able to show good sickle-kick skills as well. Thus it can be said that sicklekick skills can increase as the reaction rate increases so that athlete performance will also increase.

\section{Explosive muscle limb power has a direct positive effect $(\mathrm{X1})$ on self-confidence $(\mathrm{X} 4)$.}

The results of the research on the hypothesis that the explosive power of leg muscle (X1) and self-confidence (X4) yielded the alleged model, that $\mathrm{Y}=30,934+0,359 \mathrm{X} 1$. The results of variance analysis (ANAVA) on this model are presented in Table 4:15. In this table can be seen that the obtained value of F-count 6.271 obtained value F-table $=(0.05,1: 28)$ of 4.20 with a significant level of 0.018 . Thus it can be argued that the regression equation is significant.

Double correlation coefficient $(\mathrm{R})$ obtained value of 0.428 after consultation with r-table on degrees of freedom 29 with $\alpha=0.05$ of 0.311 then variable X1 to X4 significantly positive correlated. $\mathrm{R}$ Square (coefficient of determination) obtained value of 0.183 , which means $18.3 \%$ of the total 
confidence variation (X4) caused by multiple regression relationship variable explosive muscle limb power (X1). This means that $18.3 \%$ of explosive muscle limb power data (X1) gives a direct effect on self-confidence (X4) and the rest of $81.7 \%$ or $(100 \%-18.3 \%=81.7 \%)$ Other factors such as: mental state, nutrition, recovery, health condition of athletes, and others.

Furthermore, the result of $\mathrm{t}$-test calculation is obtained $\mathrm{t}$-count $=2.504$ and $\mathrm{t}$-table $(0,05)=$ 1,697 with significant level 0,018 smaller than $\alpha=0,05$, so t-count is bigger than t-table, $\mathrm{H} 0$ is rejected, and $\mathrm{H} 1$ is accepted. From the calculation results can be stated that the hypothesis proposed: power muscle leg explosion (X1) positive direct positive effect on confidence (X4) received. The results of this hypothesis analysis provide findings that the explosive power of leg muscles has a direct positive effect on the speed of the reaction. This finding means that if you want to increase the speed of the reaction then it can be done through increasing the muscle limb power.

Based on the correlation coefficient, will be obtained coefficient of determination of 0.183 so that the findings in this study indicate the importance of variable explosive leg muscle to increase reaction speed, because it can explain the variation of skill sickle kick at $18.3 \%$. This is in line with the theory of each of the independent variables described in the preceding section.

\section{Eye-foot coordination has a direct positive effect (X2) on self-confidence (X4).}

The results of the hypothesis that the eye-foot coordination (X2) and self-confidence (X4) yielded the alleged model, that $\mathrm{Y}=26,604+0,450 \mathrm{X} 2$. The results of variance analysis (ANAVA) on this model are presented in Table 4.17. In this table can be seen that the obtained value F-count 7.692 obtained value F-table $=(0.05,1: 28)$ of 4.20 with a significant level of 0.010 . Thus it can be argued that the regression equation is significant.

Double correlation coefficient $(\mathrm{R})$ obtained value of 0.464 after consultation with r-table on degrees of freedom 29 with $\alpha=0.05$ of 0.311 then variable $\mathrm{X} 2$ to $\mathrm{X} 4$ significantly positive correlated. R Square (coefficient of determination) obtained a value of 0.216 , which means $21.6 \%$ of the total confidence variation (X4) is caused by multiple regression relationships variables eye-foot coordination (X2). This means that $21.6 \%$ eye-foot coordination data (X2) gives a direct effect on self-confidence (X4) and the rest of $78.4 \%$ or $(100 \%-21.6 \%=78.4 \%)$ Other factors such as: mental state, nutrition, recovery, health condition of athletes, and others.

The result of t-test is $\mathrm{t}$-count $=2,773$ and $\mathrm{t}$-table $(0,05)=1,697$ with significant level 0,010 smaller than $\alpha=0,05$, t-count is bigger than t-table, $\mathrm{H} 0$ is rejected, and $\mathrm{H} 1$ is accepted. From the calculation results can be stated that the hypothesis proposed: eye-foot coordination (X2) positive direct positive effect on confidence (X4) received. The results of the hypothesis analysis presented suggest that eye-foot coordination has a direct positive effect on self-confidence. This finding means that if you want to increase confidence it can be done through increased eye-foot coordination exercises.

\section{The reaction rate has a direct positive effect (X3) on self-confidence (X4).}

Result of research about hypothesis which stated that reaction velocity (X3) have positive effect to confidence $(\mathrm{X} 4)$ yielded alleged model, that $\mathrm{Y}=22,342+0,552 \mathrm{X} 3$. The result of variance analysis (ANAVA) on this model is presented in Table 4.19. In this table can be seen that the obtained value of F-count 11.056 obtained value F-table $=(0.05,1: 28)$ of 4.20 with a significant level of 0.002 . Thus it can be argued that the regression equation is significant.

Double correlation coefficient (R) obtained value equal to 0,880 after consultation with r-table at degrees of freedom 29 with $\alpha=0,05$ equal to 0,311 then variable X3 to X4 significant positive correlation.

R Square (coefficient of determination) obtained value of 0.283 , which means $28.3 \%$ of the total confidence variation (X4) caused by multiple regression relationship variable speed of reaction (X3). This means that $28.3 \%$ of the reaction rate data (X3) gives a direct effect on confidence (X4) and 
the rest of $71.7 \%$ or $(100 \%-28.3 \%=71.7 \%)$ is caused by other factors such as: mental state, nutrition, recovery, health conditions athletes, and others.

Furthermore, from result of t-test calculation t value $=3,325$ and where $\mathrm{dk}=\mathrm{n}-2(30-2=26)$ t-table $(0,05,30-2=26)=1,697$ with significant level 0,001 less than $\alpha=0,05$, thus $t$ count is greater than t-table, $\mathrm{H} 0$ is rejected, and $\mathrm{H} 1$ is accepted. From the calculation results can be stated that the hypothesis proposed: reaction speed (X3) positive direct positive effect on confidence (X4) received. The results of the hypothesis analysis presented suggest that eye-foot coordination has a direct positive effect on self-confidence. This finding means that if you want to increase your confidence you can pay attention to the speed of the reaction.

Overall, it can be concluded that after the statistical test of the empirical data obtained from the field, it can be said that the three free variables of explosive muscle limb power, eye-foot coordination and reaction velocity have a significantly positive direct effect with sickle-kick skills.

\section{Limb muscle explosive power directly positive effect on eye-foot coordination.}

The values required to see the positive direct effect of explosive leg muscle power (X1) on eyefoot coordination (X2) yielded the alleged model, that $\mathrm{Y}=11.402+0.761 \mathrm{X} 1$. The results of variance analysis (ANAVA) on this model are presented in Table 4.21. In this table can be seen that obtained value F-count 32.005 obtained value F-table $=(0.05,1: 28)$ of 4.20 with a significant level of 0.000 . Thus it can be argued that the regression equation is significant.

Double correlation coefficient (R) obtained value of 0.880 after consultation with r-table on degrees of freedom 29 with $\alpha=0.05$ of 0.311 then the variable X1 to X2 positively correlated significantly.

R Square (coefficient of determination) obtained value of 0.775 , which means $77.5 \%$ of the total variation in the size of eye-foot coordination (X2) caused by multiple regression relationships variable explosive muscle limb power (X1). This means that $77.5 \%$ limb muscle explosive power data (X1) gives a direct effect of eye-foot coordination (X2) and the rest of $22.5 \%$ or $(100 \%-77.5 \%=$ $22.5 \%$ ) is caused by factors - other factors such as: mental state, nutrition, recovery, health condition of athletes, and others.

From the calculation result of regression coefficient above, the value of $t=9,820$ and $t$-table $(0,05)=1,697$ with significant level 0.000 smaller than $\alpha=0,05$, so t-count is bigger than t-table, $\mathrm{H} 0$ is rejected and $\mathrm{H} 1$ is accepted. From the calculation results can be stated that the hypothesis proposed: power muscle leg explosion (X1) positive direct effect on eye-foot coordination (X2) received. The result of the hypothesis analysis presented the finding that limb muscle explosion has a direct positive effect on eye-foot coordination. These findings mean that if you want to improve eye-foot coordination then you can pay attention to the explosive power of the leg muscles.

\section{Limb muscle explosive power directly affects positive reaction speed}

The values required to see the positive direct effect of explosive power of the leg muscle (X1) on the reaction velocity $(\mathrm{X} 3)$ yielded the alleged model, that $\mathrm{Y}=13.034+0.700 \mathrm{X} 1$. The results of variance analysis (ANAVA) on this model are presented in Table 4.23. In this table it can be seen that the value obtained F-count 84.166 obtained value F-table $=(0.05,1: 28)$ of 4.20 with a significant level of 0.000 . Thus it can be argued that the regression equation is significant.

Double correlation coefficient $(\mathrm{R})$ obtained value of 0.866 after consultation with r-table on degrees of freedom 29 with $\alpha=0.05$ of 0.311 then variable X1 to X3 significantly positive correlated. $\mathrm{R}$ Square (coefficient of determination) obtained a value of 0.750 , which means $75.0 \%$ of the total reaction rate velocity $(\mathrm{X} 3)$ caused by multiple regression relationship variable explosive muscle limb power (X1). This means that $75.0 \%$ limb muscle explosive power data (X1) gives a direct effect of 
reaction speed (X3) and the rest of $25.0 \%$ or $(100 \%-75.0 \%=25.0 \%)$ is caused by factors such as: mental state, nutrition, recovery, health conditions athletes, and others.

From the calculation result of regression coefficient above, obtained t-count $=9,174$ and t-table $(0,05)=1,697$ with significant level 0,001 smaller than $\alpha=0,05$, so t-count is bigger than t-table, mean $\mathrm{H} 0$ is rejected, and $\mathrm{H} 1$ accepted . From the calculation results can be stated that the hypothesis proposed: power muscle leg explosion (X1) positive direct positive effect on reaction speed (X3) received. The result of the hypothesis analysis presented the finding that the explosive power of leg muscle has a direct positive effect on the speed of the reaction. This finding means that if you want to increase the speed of the reaction it can pay attention to the explosive power of the leg muscles.

\section{Foot-eye coordination has a direct positive effect on reaction speed.}

The values required to see the positive direct effect of eye-foot coordination (X2) on the reaction velocity $(\mathrm{X} 3)$ yield the alleged model, that $\mathrm{Y}=7.123+0.828 \mathrm{X} 2$. The result of variance analysis (ANAVA) on this model is presented in Table 4:25. In this table can be seen that obtained value Fcount 101.596 obtained value F-table $=(0.05,1: 28)$ of 4.20 with a significant level of 0.000 . Thus it can be argued that the regression equation is significant.

Double correlation coefficient $(\mathrm{R})$ obtained value of 0.885 after consultation with r-table on degrees of freedom 29 with $\alpha=0.05$ of 0.311 then the variable X2 to X3 correlated positively significantly.

R Square (coefficient of determination) obtained value of 0.784 , which means $78.4 \%$ of the total reaction rate velocity (X3) is caused by multiple regression relationship of eye-foot coordination variables (X2). This means that $78.4 \%$ eye-foot coordination data (X2) gives a direct effect of reaction velocity (X3) and the rest of $21.6 \%$ or $(100 \%-78.4 \%=21.6 \%)$ is caused by factors such as: mental state, nutrition, recovery, health conditions athletes, and others.

From the calculation result of regression coefficient above, obtained t-count $=10,079$ and $t$ table $(0,05)=1,697$ with significant level 0.000 less than $\alpha=0,05$, so t-count is bigger than t-table, mean $\mathrm{H} 0$ is rejected, and $\mathrm{H} 1$ accepted. From the calculation results can be stated that the hypothesis proposed: eye-foot coordination (X2) positive direct effect on reaction speed (X3) received. The results of the hypothesis analysis presented suggest that eye-foot coordination has a direct positive effect on the speed of the reaction. This finding means that if you want to increase the speed of the reaction it can pay attention to eye-foot coordination.

\section{CONCLUSION}

From the results of hypothesis testing and discussion of research results, can be drawn the following conclusions: (1) Explosive muscle leverage directly positive effect on the crescent sickle capability. (2) Eye-foot coordination has a direct positive effect on the crescent sickness. (3) The reaction rate has a direct positive effect on the crescent sickness. (4) Confidence has a direct positive effect on the crescent sickness. (6) Limb muscle explosive power directly affects the rate of kayak reaction. (7) Biomotor ability has a direct positive effect on reaction speed. (8) Confidence has a direct positive effect on the rate of reaction. (9) Limb muscle explosive power has a direct positive effect on eye-foot coordination. (10) Limb muscle explosive power directly affects the reaction speed.

\section{REFERENCE}

Bompa, Tudor o. (2009). Theory and Methodology of Training, IOWA: Kendal / Hunt Publishing Company.

Ginnis, Mc., Peter Merton. (2005). Biomechanics of Sport and Exercise Seven Edition. United States of America: Human Kinetics. 
Hill, McGraw. (2008). Mader"s Understanding Human Anatomy \& Physiology Sixth Edition. New York: Published by McGraw-Hill.

IPSI. 2012). Pencak Silat Game Rules. Jakarta, IPSI.

Jan, A.Pandey. (1997). Technique and Term Pencak Silat. Jakarta: PB. IPSI.

Ministry of Youth and Sport, National Accreditation Institute of Sports, 2007. Basic Coaching Theory. Jakarta.

Lubis, Johansyah. (2014). Pencak Silat Practical Guide. Jakarta: PT. Rajagrafindo Persada.

Lubis, Johansyah. (2004). PB Training institutions. IPSI. Talent Talent Intruments. Jakarta: Directorate of Sports Student and Student, Directorate General of Sport of National Education.

Maksum, Ali. (2008). Sports Psychology Theory and Applications. Surabaya: Unesa University Press. Maryono, O'ong. (2008). Penak Silat Spanning Time. Yogyakarta: Red Thread.

Satiadarma, Monti p. (2000). The Basics of Sports Psychology. Jakarta: Pustaka Sinar Harapan.

Schmidt, Rickard A, PHD. (1988). Motor control and Learning A Behavioral Emphasis. Los Angles: Human Kinetics Publishers, Inc.

Sedarmayanti and Syarifuddin Hidayat. (2011). Research methodology. Bandung: Mandar Maju.

Sengkey, Augustine Reffly jeffry. (2002). Table Tennis Skills, Correlational Studies between Confidence, Speed Reaction and Kinesthetic Perception with Playing Skills Table Tennis On North Sulawesi Players. PPS UNJ: Dissertation.

Sukmadinata, Nana Syaodih. (2010). Educational Research Methods. Bandung: Teens Rosdakarya.

Tangkudung, James., Wahyuningtias Pusitorini. (2012). Coaching Sports Achievement Achievement edition II. Jakarta: Smart Jaya ..

Tangkudung, James. (2006). Physiology. Jakarta: Smart Jaya.

Law of the Republic of Indonesia Number 3 Year (2005). About the National Sport System

Vealey, R.S. (2016). Sources of Sport-Confidence: Conceptuallization and Instrumen Development. Journal of Sport and Exercise Psychology, vol.25. (diakses:25 Januari) 